\title{
The Research of Tank Bottom Structure Failure Based On Numerical Simulation
}

\author{
Mulin Zheng ${ }^{1, a}$, Min Wang ${ }^{1, b}$, Yanting $X u^{1, c}$, Jiele $X u^{2, d}$, Weican Guo ${ }^{1, e}$ \\ ${ }^{1}$ Zhejiang provincial special equipment inspection and research institute, Hangzhou 310020, China; \\ ${ }^{2}$ Zhejiang safety special equipment inspection \& testing CO., LTD, Hangzhou 310020, China. \\ amulinzheng@126.com, wangmin@nbu.edu.cn, cyanting_xu@126.com, d121498386@qq.com, e g \\ wcndt@126.com
}

Keywords: tank bottom, structure failure, numerical simulation.

\begin{abstract}
The structural failure of storage tank under internal overpressure mainly have two forms: uplift deformation and corner weld avulsion. And tank bottom is a sensitive position. A practical case of tank bottom deformation was detected in 2014. Based on this practical engineering case, tank bottom structure failure under the condition of internal overpressure on storage tank are analyzed. Then, the numerical simulation model of structural failure of tank bottom are established. The results of numerical simulation of crack propagation illustrated that the damage dissipation energy of crack propagation in the fillet weld is less than that of other location, namely the position of fillet weld is more possible to generate crack propagation. Therefore, it is necessary to do the periodic inspection of the fillet weld in tank bottom, which could find the crack in time and avoid further crack propagating.
\end{abstract}

\section{Introduction}

The atmospheric vertical storage tanks, as the important storage carrier, are widely used in petroleum and petrochemical industry. Under the erosion of natural environment and change of working conditions, the tank appeared inevitably material aging, and mechanical property decreased greatly.

There are some calculation methods proposed for the reliability of design parameters of storage tank system. A fuzzy critical state equation for describing failure of leak-free tank was established according to the theories of fracture mechanics and fuzzy reliability [1]. Chen Zhiping [2-3] improved the precision of stress calculation of large unanchored oil storage tanks and presented a new method based on a combined cylindrical shell theory. The effect of several important factors on the stress of shell-to-bottom fillet welds was analyzed numerically, such as the thickness of the annular plate, the width of the annular plate [4]. Jae-Seong Kim [5] performed a tensile test, a hardness test, and a corrosion test (SSRT) to identify the reason of the fillet weld crack failure.

In this paper, the fillet weld fracture failure of practical case was caused by overpressure. The numerical simulation models of crack propagation and fracture failure of fillet weld are established. Based on the theory of fracture mechanics, the extended finite element method is applied to fillet weld fracture failure.

\section{Cracking failure analysis of tank}

In August 2014, an unanchored storage tank with volume of $235 \mathrm{~m}^{3}$, contained methyl diethanolamine, had a lift-off deformation in tank bottom, the maximum distance of tank bottom was $200 \mathrm{~mm}$. The fracture failure state of fillet weld is shown in Fig. 1.

In preliminary analysis, we can deduce that the accident is caused by the tank breather valve failed to work. The serious overpressure in tank lead to lift-off deformation in tank bottom. The fracture failure of fillet weld is caused by serious corrosion defects and stress corrosion cracking (SCC). In working condition of overpressure, the serious stress concentration in fillet weld aggravated defects 
expanding. In order to get accurate conclusions for the failure of the storage tank, the simplified mechanical model of deformation is established, shown in Fig. 2.

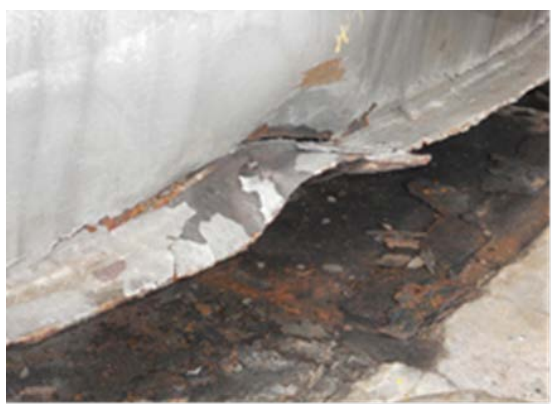

Fig. 1 Tank bottom deformation

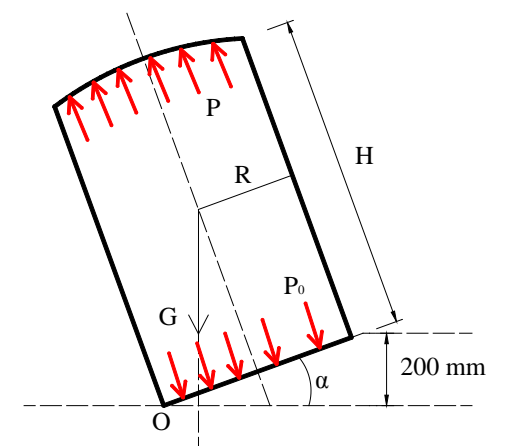

Fig. 2 Simplified mechanical model

The maximum height between tank bottom and tank base is $200 \mathrm{~mm}$, the tilting angle $\alpha$ is very small, only $3.8^{\circ}$, and the gravity $G$ acts in the center line of the symmetry. According to the principle of the mechanical equilibrium, the equation of tank deformation is:

$$
\left(P \times S-P_{0} \times \pi R^{2}\right) \times R=\left(R-\frac{H}{2} \tan a\right) \times M \times g
$$

$P$-internal pressure;

$S$ - the surface area of tank roof;

$R$ - the radius of the tank

$H$ - the height of tank;

$M$ - the quality of tank;

$P_{0}$ - the liquid static pressure.

According the site test, $P=0.054 \mathrm{MPa}$, and tank internal pressure is $0.054 \mathrm{MPa}$, it could cause the lift-off deformation of tank bottom. The maximum tilting height could determine that the condition of tank accident.

\section{Numerical simulation of lift-off deformation in tank bottom}

In order to get more accurate calculation results, a numerical simulation model was established, shown in Fig. 3. The thickness of tank wall is $6 \mathrm{~mm}$, inner diameter is $3000 \mathrm{~mm}$, height is $8656 \mathrm{~mm}$, the diameter of tank bottom is $3060 \mathrm{~mm}$. Storage tank material is Q235, the elasticity modulus is $E=210 \mathrm{GPa}$, Poisson ratio is $\mu=0.3$, yield strength is $\sigma_{y}=235 \mathrm{MPa}$, tensile strength is $\sigma_{b}=375 \mathrm{MPa}$.

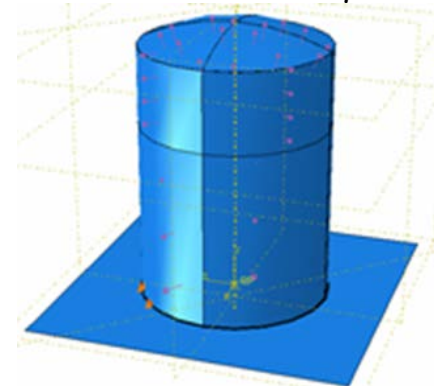

Fig. 3 Simulation model of tank bottom lift-off deformation

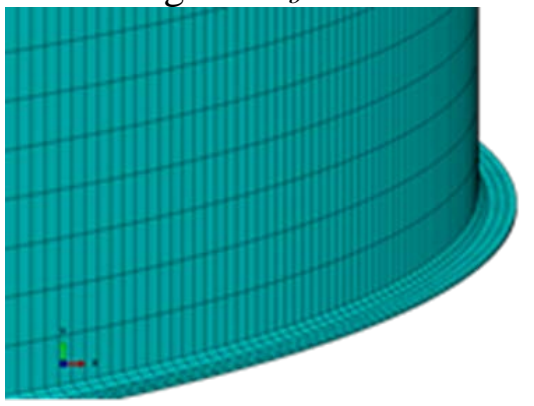

Fig. 4 Local mesh of storage tank

Then the relationship between inner overpressure and bottom lift-off deformation is determined. The tank bottom is simplified as a rigid plate in the simulation analysis. The gravity of tank and medium is considered, internal pressure $P$ acts on the tank roof and tank wall. In addition, the storage tank is also influenced by the static pressure of liquid medium $P_{s}$, the height of medium liquid level is $5500 \mathrm{~mm}$, and the static pressure of liquid medium $P_{s}$ can be obtained by:

$$
p_{s}=\rho_{l} \mathrm{~g}(5500-y)
$$

$y$ - the vertical height of liquid medium; 
$\rho_{l}$ - the density of liquid medium.

The liquid medium is methyl diethanolamine, $\rho_{l}=1.04 \times 103 \mathrm{~kg} / \mathrm{m}^{3}$, the gas internal pressure is $0.04 \mathrm{MPa}$, the liquid static pressure is $P_{s}$; and the local mesh of storage tank is shown in Fig.4.

The overall lift-off deformation of storage tank is shown in Fig. 5. According to the numerical simulation model, the maximum height of the tank bottom lift-off is $138.36 \mathrm{~mm}$. Under the same static pressure of the medium, the gas phase internal pressure of the unanchored tank is serious overpressure, which leads to the upward force of the tank higher than the sum of total gravity.

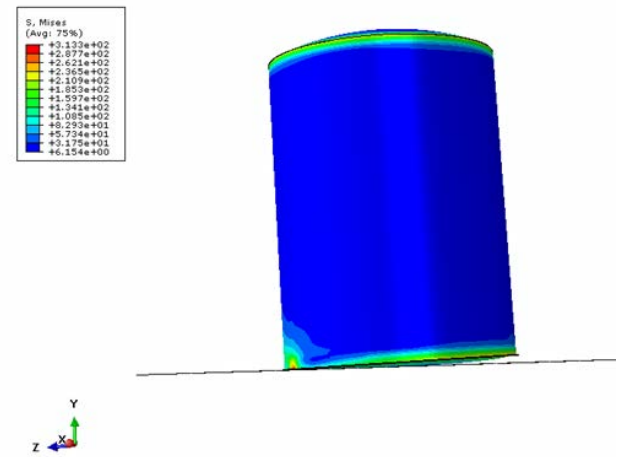

Fig. 5 Overall deformation of storage tank

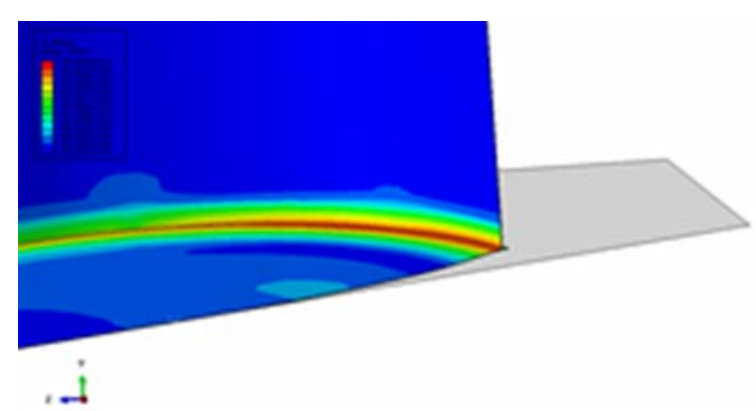

Fig. 6 The deformation of tank bottom

In addition, the medium static pressure causes the tank bottom to form the bowl shaped deformation, shown in Fig. 6. Meanwhile, the result of numerical simulation indicated that tank fillet weld have large local stress, as structural discontinuity cause the local stress concentration.

In order to get a clear and definite relationship between the internal pressure and the lift-off deformation of the tank bottom, the numerical simulations are carried out for further study. The internal pressure $P$ is set as $0.006 \mathrm{MPa}, 0.01 \mathrm{MPa}, 0.015 \mathrm{MPa}, 0.02 \mathrm{MPa}$, and $0.028 \mathrm{MPa}$, respectively, and then the relationship between the maximum lift-off height and the internal pressure $P$ can be carried out, the maximum lift-off height of the tank bottom is:

$U_{2}=\left(a \times P^{2}+b \times P+c\right) \times 10^{5}$

$U_{2}$ - the maximum lift-off height of the tank bottom, mm;

$a, b$ - coefficient;

$c$ - constant.

In this practical case, $a=2.0721, b=-0.0638$, and $c=0.0006$, so equation (3) is:

$U_{2}=\left(2.0721 \times P^{2}-0.0638 \times P+0.0006\right) \times 10^{5}$

Through the above analysis, we can get the conclusion that the lift-off deformation of tank bottom is mainly caused by the serious internal overpressure of gas. And when the internal pressure $P$ reach at $0.046 \mathrm{MPa}$, the maximum height of lift-off deformation of tank bottom is $U_{2}=200 \mathrm{~mm}$.

\section{Numerical simulation of fillet weld}

The extended finite element method (XFEM) [6] is a very effective numerical solution method for the discontinuous mechanics problems. So we adopt the extended finite element method to simulate the crack propagation of fillet weld.

The energy release rate was adopted to define the damage evolution by using the B-K rule, and the fracture energy is $G_{I}=G_{I I}=G_{I I I}=70 \mathrm{~N} / \mathrm{mm}$.

In order to simplify the calculation of crack propagation of fillet weld, partial structure is taken as the numerical model. The circumference angle of tank bottom is $5^{\circ}$. The internal pressure is $0.045 \mathrm{MPa}$. The length of pre-crack is $35 \mathrm{~mm}$, and the width is $6 \mathrm{~mm}$. The pre-crack is located in the fillet weld and the extend board of tank bottom with a certain angle is labeled as crack A, B and C respectively, shown in the Fig. 7.

Based on the extended finite element method, the numerical simulation on the pre-crack shows that there are three types of cracks occurred on the propagation in different levels under internal overpressure, shown in the Fig. 7. It will cause lift-off deformation in storage tank, and the crack will 
grow up as the combined effects of local stress concentration and hoop tensile stress, and the fillet weld will tear out finally.

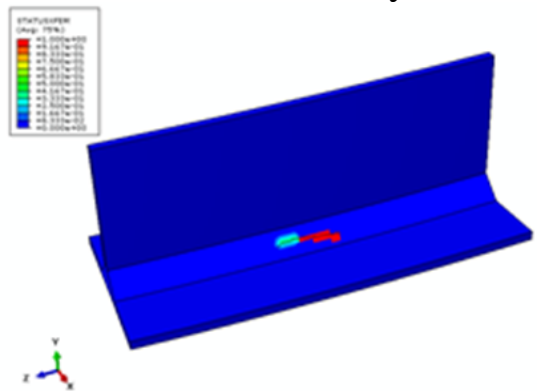

(A) crack A

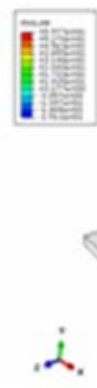

(B) crack B
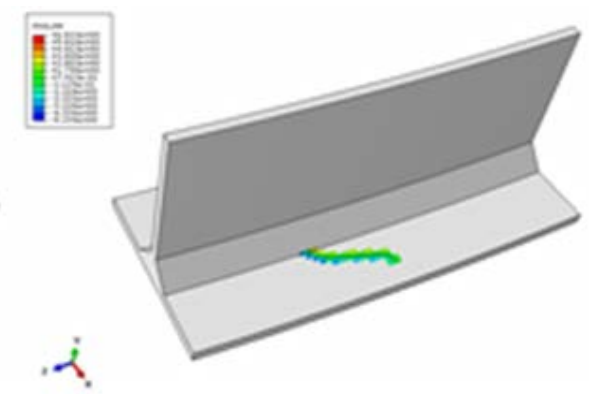

(C) crack C

Fig.7 Crack propagation

The propagation depth of crack A is much deeper than crack B, shown in Fig. 7. Crack A belongs to crack type I as there is an inclination angle between crack A and hoop. It is beneficial to the growth of crack. Similarly, crack $C$ has the maximum growth depth of the three cracks in extended board. Crack $\mathrm{C}$ with larger inclination angle shows that the hoop tensile stress has an effect on the crack propagation.

\section{Conclusion}

In this paper, a numerical simulation model of atmospheric storage tank is established, and the parameters of fracture failure of fillet weld in tank bottom is calculated. We can get the conclusions as follows:

(1) Under the internal overpressure, the unanchored storage tank would generate the lift-off deformation and the fillet weld fracture failure in bottom;

(2) Structure discontinuity and serious local stress concentration coexist in fillet welds. When the storage tank occurred deformation there is a stress corrosion crack in fillet weld. The crack failure of fillet weld is caused by stress concentration and corrosion influence.

(3) The simulation of crack propagation of the fillet weld illustrated that the damage dissipation energy of crack propagation in the fillet weld is less than that of other location, and this location is more beneficial for crack propagation. Therefore, the periodic inspection of the fillet weld in tank bottom is necessary to avoid further crack propagating in practical engineering.

\section{Reference}

[1] Liu, Y., Zhao, H. J., Dong, J. M., et al, Reliability Analysis of Tank at Normal Pressure, J. ACTA Petrolei Sinica (Chinese), 23(2002), 96-100.

[2] Chen, Z. P., Wang, F., Shen, J. M., et al, Stress Analysis on Large Unanchored Oil Storage Tanks, J. Chinese Journal of Mechanical Engineering (Chinese), 42(2006), 206-212.

[3] Chen, Z. P., Ge, S., Shen, J. M., et al, New Modeling Method for Finite Element Analysis of Large Oil Storage Tanks, J. Journal of Zhejiang University (Engineering Science) (Chinese), 40(2006), 977-981

[4] Chen, Z. P., Jiang, W. H., Shen, J. M., et al, Analysis of the Stress around the Shell- to- bottom Fillet Welds of Large Oil Tanks, J. Pressure Vessel Technology (Chinese), 22(2005), 12-15

[5] Kim, J. S., An, D. H., Lee, S. Y., et al, A Failure Analysis of Fillet Joint Cracking in An Oil Storage Tank, J. Journal of Loss Prevention in the Process Industries, 22(2009), 845-849.

[6] Daux, C., Moes, N., Dolbow, J., et al, Arbitrary branched and intersecting cracks with the extended finite element method, J. International Journal for Numerical Methods in Engineering, 48(2000), 1741-1760. 